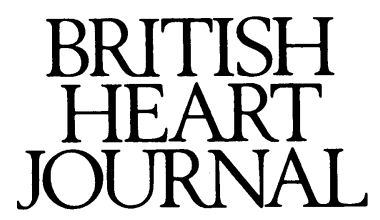

Editorial

\title{
Stress proteins, self defence, and the myocardium
}

Despite advances in the treatment of coronary artery disease, the search for ways to preserve myocardium threatened by ischaemic or reperfusion injury continues. A group of proteins known as the heat shock or stress proteins represent the cell's innate ability to protect itself. Do these proteins have a role in protecting the heart in coronary artery disease and can this self preservation mechanism be exploited therapeutically?

Heat shock proteins were originally described in the $1960 \mathrm{~s}^{1}$ and over the next two decades the concept of thermotolerance developed. It was discovered that cells and organisms exposed to sublethal hyperthermia synthesised stress proteins ${ }^{2}$ and were rendered tolerant or resistant to subsequent hyperthermic stress. This group of inducible stress proteins is phylogenetically well preserved, being present in various organisms from bacteria to humans. ${ }^{3}$ It is unlikely that their expression in mammals is merely an evolutionary remnant of little relevance to homoeothermic animals, since their induction is not confined to the stimulus of heat. Other stimuli include various metabolic stressors such as cellular hypoglycaemia, reactive oxygen species (hydrogen peroxide and superoxide), and ischaemia ${ }^{5}$-all factors that suppress the synthesis of other cellular proteins.

Animal studies have shown that after preconditioning with a brief period of ischaemia the heart is temporarily protected from further ischaemic episodes, ${ }^{6}$ and recent evidence suggests that this phenomenon also exists in humans. ${ }^{7}$ In addition, a constitutively (basally) expressed stress protein of the $70 \mathrm{kDa}$ heat shock protein (HSP70) family is selectively inducible in rabbit heart by ischaemia. ${ }^{5}$

It is well recognised that heat shock and the subsequent synthesis of stress proteins is protective ${ }^{8}$ whether stress proteins contribute to myocardial preconditioning remains controversial. Attention to date has focused on the $70 \mathrm{kDa}$ stress protein, which has been well reviewed. ${ }^{89}$

A role for stress proteins in myocardial preconditioning was supported by work that showed that rendering animals hyperthermic (thus inducing the heat shock protein response) before an episode of cardiac ischaemia had a protective effect both during the ischaemic period and on restoration of perfusion. ${ }^{1011}$ However, a few minutes of myocardial ischaemia has been shown to exert a protective effect, preconditioning the heart against subsequent ischaemic episodes. ${ }^{67}$ Such a time course suggests that this preconditioning effect is unlikely to be due to stress protein induction: increased expression of HSP70 mRNA is not seen in rabbits until an hour after a short ischaemic period, and an increase in the stress protein itself is only detected after two hours, peaking at 24 hours. ${ }^{5}$ In addition, it has been shown that protein synthesis is not a prerequisite for preconditioning. ${ }^{12}$

A further group of stress proteins may contribute to the myocyte's defences. The glucose-regulated stress proteins are induced by cellular hypoglycaemia, a state that occurs during ischaemia when the synthesis of other proteins is suppressed. ${ }^{13}$ Though little is known of their functions, they may modulate the response of the myocyte to hypoxia, perhaps by regulating the folding and assembly of proteins disrupted by hypoxia. ${ }^{14}$

Stress proteins also seem to have a role in myocardial adaptation (by hypertrophy), to haemodynamic overload. ${ }^{15}$ Cardiomyocytes adapt rapidly to pressure overload with increased protein synthesis. Though the bulk of such proteins comprise contractile units, increased expression of the HSP70 gene is detected as early as an hour after the onset of pressure overload, followed by the appearance of the HSP70 protein. This induction is a short-lived phenomenon; concentrations of HSP70 mRNA return to baseline after 24 hours despite continuous pressure overload. Although the transience of their induction suggests that stress proteins are not the sole cause of compensatory hypertrophy, their perinuclear distribution implies that they may have a permissive role in mediating overloadinduced hypertrophy. By the mechanisms discussed below they may permit the rapid recovery of protein synthesis interrupted by the onset of overload, thus enabling the cell to survive the initial stress and to adapt by hypertrophy to continued overload.

What are the mechanisms by which stress proteins provide protection? It has been hypothesised that they recognise and repair hypoxia-induced damage to cellular proteins; ${ }^{1416}$ rescue protein synthesis and mRNA splicing halted by the onset of stress; $;^{17}$ and are involved in protein folding and unfolding, assembly and disassembly, and translocation. ${ }^{19} \mathrm{~A}$ further possibility is that stress proteins exert their effect by affording protection against the oxidative stress of reactive oxygen species liberated during post-ischaemic reperfusion: heat shock is accompanied by the induction of the antioxidant catalase within the myocardium. ${ }^{10}$ Inhibition of catalase induction has been shown to lessen the protective effect of heat shock. ${ }^{20}$

Do stress proteins protect the heart by other antioxidant mechanisms? A low molecular weight stress protein (SP32) is present in the heart ${ }^{21}$ and induced by the reactive oxygen species, hydrogen peroxide..$^{22}$ Reactive oxygen species are released early during post-hypoxic reperfusion and have been implicated in myocardial reperfusion injury. SP32 has been identified as haem oxygenase $-1,22$ the rate limiting enzyme in the degradation of haem to bilirubin. Bilirubin is a potent scavenger of reactive oxygen species, its efficacy increasing with the decrease in $\mathrm{pH}^{18}$ associated with ischaemia. Haem oxygenase-1 (SP32) is active only in the presence of oxygen. It is therefore possible that during reperfusion (for example after thrombolysis for myocardial infarction) the induction of haem oxygenase- 1 mediated by reactive oxygen species has a protective antioxidant effect.

It may therefore be hypothesised that the heart is 
protected by the innate ability of the cardiomyocyte to defend itself against hypoxic, oxidant, and haemodynamic stress by the induced expression of a stress protein response. The heart is not unique in this respect: the inflamed joint shows striking similarities. ${ }^{24}$ It too is subject to pressure-induced ischaemia and reperfusion events that facilitate the generation of reactive oxygen species and the induction of protective stress proteins. ${ }^{25}$ Additionally, the $60 \mathrm{kDa}$ stress protein family has been implicated in inflammatory arthritis, ${ }^{26}$ inviting speculation that because of the highly conserved nature of stress proteins, molecular mimicry may lead to the development of autoimmunity. ${ }^{28}$

Some fundamental questions remain. Do the stress proteins provide the heart with purely a self defence mechanism or can they also attack (for example in autoimmune conditions such as Dressler's syndrome and lupus carditis)? While research to elucidate the molecular biology of the stress proteins continues, questions about their therapeutic exploitation should be considered. Has this already been achieved during surgery by the hypothermic induction of protective stress proteins during cold cardioplegia and organ transport? Finally, will pharmacological intervention prolong or stimulate the induction of stress proteins, thereby providing a means to protect the myocardium in coronary artery disease?

S A THORNE V R WINROW*

Department of Cardiology and Inflammation Research Group, AKE* Royal London Hospital, Whitechapel,

\section{London E1 1BB}

SAT is supported by a British Heart Foundation Research Fellowship, VRW is supported by the Arthritis and Rheumatism Council (ARC) and DRB has an endowed ARC professorship held by the London Hospital Medical College.

1 Ritossa F. A new puffing pattern induced by temperature shock and DNP in Drosophila. Experentia 1962;18:571-3.

2 Carper SW, Duffy JJ, Gerner EW. Heat shock proteins in thermotolerance and other cellular processes. Cancer Res 1987;47:5249-55.

3 Schlesinger MJ, Ashburner M, Tissieres A, eds. Heat shock: from bacteria to man. Cold Spring Harbour Laboratory Press, 1982:1-440.

4 Donati YRA, Slosman DO, Polla BS. Oxidative injury and the heat shock response. Biochem Pharmacol 1990;40:2571-7.

5 Knowlton AA, Brecher P, Apstein CS. Rapid expression of heat shock proteins in the rabbit after brief cardiac ischaemia. J Clin Invest 1991;87:139-47.
6 Reimer KA, Murry CE, Jenning RB. Cardiac adaptation to ischaemia. Circulation 1990;82:2266-8.

7 Deutsch E, Berger M, Kessmaul WG, Hirschfield JW, Laskey WK. Adaptation to ischaemia during percutaneous transluminal coronary angioplasty. Ctrculation 1990;82:2044-51.

8 Currie RW, Ross BM, Davies TA. Induction of the heat shock response in rats modulates heart rate, creatine kinase and protein synthesis after a subsequent hyperthermic treatment. Cardiovasc Res 1990;24:87-93.

9 Stress proteins and myocardial protection. Lancet $1991 ; 337 \cdot 271-2$.

10 Currie RW, Karmazyn M, Kloc M, Mailer K. Heat shock response is associated with enhanced postischemic ventricular recovery. Circulation Res 1988;63:543-9.

11 Yellon DM, Pasini E, Ferrari R, Downey JM, Latchman DS. Whole body heat shock protects the isolated perfused rabbit heart [abstract]. Circulation 1990;82(suppl 111):1839.

12 Thornton JD, Sriplin S, Liu GS, Swafford A, Stanley AWH, van Winkle $\mathrm{DM}$, et al. Inhibition of protein synthesis does not block myocardial protection afforded by preconditioning. Am J Physiol 1990; 259:H1822-5.

13 Hightower LE, White FP. Preferential synthesis of rat heat shock and lucose-regulated proteins in stressed cardiovascular cells. In: Schlesinger MJ, Ashburner M, Tissieres A, eds. Heat shock: from bacteria to man. Cold Spring Harbour Laboratory Press, 1982:369-77.

14 Ellis RJ, Hemmingsen SM. Molecular chaperons: proteins essential for the biogenesis of some macromolecular structures. Trends Biochem Sci 1989; 14:339-42.

15 Delcayre C, Samuel JL, Marrotte F, Best-Belpomme M, Mercadier JJ, Rappaport $L$. Synthesis of stress proteins in rat cardiac myocytes $2-4$ days

16 Winrow VR, McLean L, Morris CJ, Blake DR. The heat shock protein response and its role in inflammatory disease. Ann Rheum Dis 1990;49: response

17 Welch WJ, Suhan JP. Morphological study of the mammalian stress response: characterisation of changes in cytoplasmic organelles, cytoskeleton and nucleoli, and appearance of internuclear actin filaments in rat fibroblasts after heat shock treatment. J Cell Biol 1985;101:1198-211.

18 Yost HJ, Lindquist S. RNA splicing is interrupted by heat shock and is rescued by heat shock protein synthesis. Cell 1986;45:185-93.

19 Lindquist S, Craig EA. The heat shock proteins. Ann Rev Genet 1988; 22:631-7.

20 Karmazyn M, Mailer K, Currie RW. Acquisition and decay of heat shockenhanced postischemic ventricular recovery. Am J Physiol 1990;259: H424-31.

21 Schuman J, Przybyla A. Expression of the $31 \mathrm{kDa}$ stress protein in rat myoblasts and hepatocytes. DNA 1988;7(7):475-82.

22 Keyse SM, Tyrell RM. Heme oxygenase is the major $32 \mathrm{kDa}$ stress protein induced in human skin fibroblasts by UVA radiation, hydrogen peroxide induced in human skin fibroblasts by UVA radiation, hydrogen

23 Stocker R, Yamamoto Y, McDonagh AF, Glazer AN, Ames BN. Bilirubin is an antioxidant of possible physiological importance. Science 1987; 235:1043-6.

24 Winrow VR, Blake DR. Stress proteins, hearts and joints. Lancet 1991;337: 614-5.

25 Allen RE, Blake DR, Nazhat NB, Jones P. Superoxide generation by inflamed human synovium after hypoxia. Lancet 1989;ii:282-32.

26 Winrow VR, Mojdehi G, Mapp PI, Rampton DS, Blake DR. Immunohistological localisation of stress proteins in inflammatory tissue. In: Burdon R, Rice-Evans C, Blake DR, Winrow V, eds. Stress Proteins in Inflammation. London: Richlieu Press, 1990;137:237-51.

27 van Eden W, Thole JER, van der Zee R, Noordzij A, van Embden JDA, Hensen EJ, et al. Cloning of the mycobacterial epitope recognised by $\mathrm{T}$ Hensen EJ, et al. Cloning of the mycobacterial epitope recogn

28 Tsoulfa G, Rook GAW, van Embden JDA, Young DB, Mehlert A, Isenberg DA, Hay FC, Lydyard PM. Raised serum IgA and IgG antibodies to mycobacterial antigens in rheumatoid arthritis. Ann Rheum Dis 1989;48:118-23. 